\title{
Densidade populacional de Ralstonia solanacearum em cultivares de batata a campo
}

\author{
Population densities of Ralstonia solanacearum on potato cultivars in the field
}

\author{
João Leodato Nunes Maciel ${ }^{1}$ Valmir Duarte ${ }^{2}$ José Ricardo Pfeifer Silveira $^{3}$
}

\section{RESUMO}

\begin{abstract}
A ocorrência de populações latentes de Ralstonia solanacearum em plantas de batata (Solanum tuberosum) pode representar fonte de inóculo de potencial desconhecido. Além disso, também é desconhecido se a população latente da bactéria é menor em cultivares resistentes do que em cultivares suscetiveis. Com a finalidade de estudar estes aspectos, um experimento foi conduzido a campo em dois locais no Estado do Rio Grande do Sul, Brasil. O objetivo foi verificar se havia relação entre a densidade populacional e o grau de resistência de cultivares de batata. $O$ experimento foi conduzido em Eldorado do Sul, durante o período de primavera, e em Caxias do Sul, durante o período de outono. Tubérculos das cultivares Achat, Baronesa, Elvira, Macaca, Monte Bonito e Trapeira foram inoculados com uma estirpe de R. solanacearum, biovar II, e plantados a campo. A densidade populacional da bactéria foi estimada em plantas com e sem sintomas de murcha, através de ELISA e imunofluorescência. Não houve evidência da relação entre densidade populacional da bactéria e cultivar. Além disso, a densidade populacional na cultivar Achat, caracterizada como a mais resistente entre as cultivares testadas, foi igual à registrada nas outras cultivares.
\end{abstract}

Palavras-chave: murcha bacteriana, Solanum tuberosum, ELISA, imunofluorescência.

\section{ABSTRACT}

The occurrence of latent populations of Ralstonia solanacearum on potato (Solanum tuberosum) plants may represent inoculum source of unknown potential. Besides, it is also unknown if the latent population of the bacterium is lower in resistant than in susceptible cultivars. In order to study these points, an experiment was conducted in the field in two locations in Rio Grande do Sul State, Brazil. The objective was to verify the relationship between $\boldsymbol{R}$. solanacearum population density and the potato cultivar resistance. The experiment was conducted in Eldorado do Sul, during the Spring, and in Caxias do Sul, during the Fall. Tubers of Achat, Baronesa, Elvira, Macaca, Monte Bonito, and Trapeira cultivars were inoculated with a $\boldsymbol{R}$. solanacearum strain, biovar II, and planted in the field. Population density of the bacterium was estimated in the assymptomatic and wilted plants, by ELISA and imunofluorescence techniques. No evidence of relationship between population density of $\boldsymbol{R}$. solanacearum and cultivar was found. Besides, the population density on Achat, known as the most resistant, one was similar to the other cultivars.

Key words: bacterial wilt, Solanum tuberosum, ELISA, imunofluorescence.

\section{INTRODUÇÃO}

Um dos principais entraves para o sucesso no controle da murcha bacteriana da batata, causada por Ralstonia solanacearum, tem sido a capacidade da bactéria sobreviver e ser disseminada sob a forma de infecções latentes (GRAHAM et al., 1979; CIAMPI \& SEQUEIRA, 1980; HAYWARD, 1991). No Brasil, tal situação é preocupante, uma vez que $70 \%$ dos produtores de batata-consumo de nosso país utilizam, como batatas-semente para o plantio, tubérculos colhidos de lavouras não submetidos a qualquer programa de inspeção de doenças e, em particular, de murcha bacteriana (LOPES, 1994). Além disso, é

\footnotetext{
${ }^{1}$ Engenheiro Agrônomo, Doutor, Estação Experimental do Arroz, Instituto Rio-Grandense do Arroz (EEA-IRGA), Cachoeirinha, RS.

${ }^{2}$ Engenheiro Agrônomo, Ph.D., Professor Adjunto, Departamento de Fitossanidade, Faculdade de Agronomia, Universidade Federal do Rio Grande do Sul, CP 776, 91540-000, Porto Alegre, RS, fax: (51) 3316-6016, E-mail: valmir@ufrgs.br. Autor para correspondência.

${ }^{3}$ Engenheiro Agrônomo, Doutor, Fundação Estadual de Pesquisa Agropecuária (FEPAGRO), Porto Alegre, RS.
} 
desconhecido o potencial que plantas das cultivares de batata plantadas no Brasil, principalmente das consideradas mais resistentes, representam como fonte de inóculo.

Na Europa, programas de melhoramento de batata e tomate têm considerado a baixa taxa de infecção latente por $\boldsymbol{R}$. solanacearum como critério para seleção de genótipos (GRYMSLEY \& WANG, 1998). No Canadá, De BOER \& MCCANN (1989; 1990) verificaram que a densidade populacional de Clavibacter michiganensis subsp. sepedonicus em plantas e tubérculos de cultivares resistentes, sob a forma latente, foi igual ou superior àquela registrada em cultivares suscetíveis. Em função destes resultados, a produção de batatas-semente naquele país, é monitorada para verificar a incidência do patógeno, através de um sistema de amostragem e da utilização de técnicas imunológicas e moleculares para detecção (McDONALD\& BORREL, 1991).

Técnicas ou procedimentos que permitem a detecção ou quantificação de bactérias fitopatogênicas constituem-se em ferramentas de grande utilidade em estudos epidemiológicos, certificação de sementes e rotinas quarentenárias. Neste contexto, células de $\boldsymbol{R}$. solanacearum presentes em plantas, tubérculos, rizomas, sementes e no solo têm sido detectadas e quantificadas através do uso de estirpes mutantes resistentes a antibióticos, da técnica de PCR e de procedimentos sorológicos como as técnicas de ELISA e de imunofluorescência (MOFFET et al., 1983; Van VUURDE, 1990; ROBINSON, 1993; ELPHINSTONE, 1994; ELPHINSTONE et al., 1996). Os resultados têm indicado que nem sempre a presença de $\boldsymbol{R}$. solanacearum significa a ocorrência de sintomas da doença.

Assim, um experimento de campo foi conduzido em dois locais no RS com o objetivo de verificar a existência de relação entre o grau de resistência de cultivares a murcha bacteriana e a densidade populacional de $\boldsymbol{R}$. solanacearum.

\section{MATERIALEMÉTODOS}

O experimento foi conduzido na primavera, em 1996, na Estação Experimental Agronômica da Universidade Federal do Rio Grande do Sul (EEA/ UFRGS), Eldorado do Sul, e no outono, em 1998, no Centro de Pesquisa de Agroindústria da Fundação Estadual de Pesquisa Agropecuária (CPA/FEPAGRO), Caxias do Sul. A EEA/UFRGS está localizada às margens da rodovia BR-290, Km 146, entre as latitudes $30^{\circ} 05^{\prime}$ e $30^{\circ} 15^{\prime}$ 'sul, e longitudes $51^{0} 30^{\prime}$ e $51^{\circ} 45^{\prime}$ oeste, apresentando altitude média de $46 \mathrm{~m}$. Situa-se em uma região que, segundo a classificação de Köeppen, apresenta clima subtropical úmido, com verão quente, sendo uma transição entre os tipos fundamentais Cfa1 (isoterma anual inferior a $18^{\circ} \mathrm{C}$ ). A temperatura média do mês mais frio é $14,8^{\circ} \mathrm{C}$, a média anual é $19,6^{\circ} \mathrm{C}$ e a média anual máxima $24,3^{\circ} \mathrm{C}$. A precipitação pluviométrica

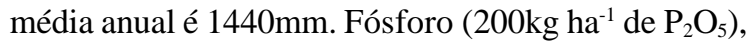
potássio $\left(90 \mathrm{~kg} \mathrm{ha}^{-1} \mathrm{de}_{2} \mathrm{O}\right)$ e calcário $\left(200 \mathrm{~kg} \mathrm{ha}^{-1}\right)$ foram incorporados durante o preparo do solo e plantio. $\mathrm{O}$ nitrogênio foi aplicado nas doses de $100 \mathrm{~kg} \mathrm{ha}^{-1}$ e $60 \mathrm{~kg}$ $\mathrm{ha}^{-1}$ nos cultivos de primavera e de outono, respectivamente. Nos dois cultivos, foram utilizados tubérculos das cultivares Baronesa, Macaca, Monte Bonito e Trapeira (batatas-semente básica); e Achat e Elvira (batatas-semente certificada). Cada cultivar foi submetida a dois tratamentos; 40 tubérculos foram mergulhados em solução tampão de fosfato (STF) $\left(\mathrm{PO}_{4}^{-2}\right.$, $0,01 \mathrm{M}, \mathrm{pH} 7,2)$, e outros 40 em STF contendo células da estirpe Rsol- $2^{\mathrm{r}+\mathrm{c}+\mathrm{e}+}$ de $\boldsymbol{R}$. solanacearum $\left(4,7 \times 10^{7}\right.$ $\mathrm{UFC} \mathrm{ml}^{-1}$ ), biovar II, raça 3 (YOSSEN et al., 1998). De cada tratamento, 8 tubérculos de cada cultivar foram plantados em parcelas de 2,4 x 1m, em delineamento de blocos casualizados. Com esta distribuição, cada tratamento teve cinco parcelas para cada cultivar. Em ambos os cultivos, o fungicida chlorothalonil foi aplicado aos 35 e 50 dias após o plantio na dose de $150 \mathrm{~g}$ i.a. $100 \mathrm{~L}^{-1}$ de água.

A incidência de plantas murchas ou mortas em cada parcela foi registrada aos 42 dias após o plantio, no cultivo de primavera e, aos 40 , no de outono. Para efeito de análise, considerou-se a incidência percentual de plantas sintomáticas nas parcelas com tubérculos inoculados, transformada em $\sqrt{x+1}$ considerando os dados obtidos dos dois cultivos.

Aos 21, 42 e 68 dias após o plantio, no cultivo de primavera, e aos 24,40 e 58 , no de outono, plantas ou brotações laterais de plantas com ou sem sintomas de murcha foram coletadas. As amostras foram pesadas e transferidas para sacos plásticos contendo tampão de extração para ELISA ( $\mathrm{NaCl}, 8$; $\mathrm{K}_{2} \mathrm{PO}_{4}, 0,2 ; \mathrm{Na}_{2} \mathrm{HPO}_{4}, 1,15 ; \mathrm{KCl}, 0,2 ; \mathrm{NaN}_{3}, 0,2 \mathrm{~g} \mathrm{~L}^{-1}$; pH 7,4 mais polyvinilpyrrolidone, 20; leite desnatado em pó, 0,01; tween-20, 0,5 $\mathrm{g} \mathrm{L}^{-1}$ ) na proporção de 2:1 (tampão de extração: peso da amostra). As amostras foram trituradas nos sacos plásticos e mantidas à $20^{\circ} \mathrm{C}$ até que todas as coletas de cada cultivo fossem feitas.

Utilizou-se o protocolo proposto pelo Centro Internacional de La Papa para execução do método do sanduíche duplo com anticorpo policlonal reativo contra $R$. solanacearum produzido pelo CPACT-EMBRAPA(CENTRO INTERNACIONALDE LA PAPA, 1990; CASTRO et al., 1993). De cada 
amostra, $100 \mu$ l do macerado em tampão de extração foi colocado em cada célula das placas de poliestireno (Nunc-Immunoplate, Maxisorp). A leitura da absorbância das reações foi feita em espectrofotômetro, em luz visível, a $405 \eta \mathrm{m}$. Suspensões de $\boldsymbol{R}$. solanacearum $\left(10^{10} \mathrm{UFC} \mathrm{ml}^{-1}\right)$ e de Xanthomonas axonopodis pv. citri em tampão de extração foram utilizados como controles positivo e negativo, respectivamente. De cada grupo de amostras, assintomáticas e sintomáticas, e de cada coleta, cinco amostras de cada cultivar foram submetidas duas vezes ao ELISA. Para análise de variância, as leituras de absorbância originais, correspondentes aos dados obtidos das amostras de plantas assintomáticas e sintomáticas, foram transformadas para $\sqrt{x+0,5} \mathrm{e}$ $\sqrt{x}$, respectivamente.

Um ml de cada amostra triturada em tampão de extração foi diluído até $10^{-10}$. Alíquotas de $20 \mu \mathrm{l}$ de cada diluição foram colocados no centro de círculos marcados em lâminas de vidro. Os demais procedimentos para quantificação da bactéria nas amostras utilizando a técnica de imunofluorescência foram os mesmos descritos por Van VUURDE (1990), sendo que o antissoro foi o mesmo utilizado no ELISA. A contagem das células bacterianas foi realizada com auxílio de microscópio de luz ultravioleta e lentes de 400 e 540 vezes de aumento. De cada grupo de amostras, assintomáticas e sintomáticas, e de cada coleta, três amostras de cada cultivar foram submetidas aos procedimentos de imunofluorescência. Para análise de variância, o número de unidades de imunofluorescência (UIF) $\mathrm{g}^{-1}$ de tecido vegetal, correspondentes aos dados obtidos das amostras de plantas assintomáticas e sintomáticas, foram de transformados para $\log x+10$ e $\log \mathrm{x}+1$, respectivamente.

\section{RESULTADOS E DISCUSSÕES}

As cultivares foram diferentes entre si quanto ao grau de resistência a murcha bacteriana somente durante o cultivo de primavera (Tabela 1), sendo a cultivar Achat a mais resistente. A Baronesa, que tem sido caracterizada como muito suscetível à doença, segundo LOPES (1994), não diferiu das cultivares Trapeira e Monte Bonito, que foram as mais suscetíveis.

Nas amostras de plantas assintomáticas, na média de cada um dos dois cultivos, verificou-se que houve diferença nos valores de absorbância nas reações do ELISA somente da cultivar Baronesa em relação ao controle (Tabela 2). Além disso, nos dois cultivos, as cultivares não se diferenciaram entre si e, inclusive do controle, em nenhuma das três avaliações realizadas em cada cultivo (dados não mostrados). Entre as amostras de plantas sintomáticas, não se verificou diferença entre as quatro cultivares nas duas avaliações iniciais realizadas durante o cultivo de primavera (Tabela 3). A diferença foi constatada somente na última coleta em que os valores de absorbância das amostras da cultivar Monte Bonito foi superior às demais.

Através de técnicas de imunofluorescência, constatou-se que, entre as plantas assintomáticas, as cultivares não se diferenciaram na média do cultivo de outono (Tabela 2). No entanto, na média do cultivo de primavera, a população estimada na cultivar Baronesa foi superior à população na cultivar Macaca. A densidade populacional média de $\boldsymbol{R}$. solanacearum presente nas plantas assintomáticas das seis cultivares foi de $7,86 \times 10^{3}$ e $7,94 \times 10^{1} \mathrm{UIF} \mathrm{g}^{-1}$ de tecido vegetal nos cultivos de primavera e outono, respectivamente. Entre as plantas sintomáticas, não foi verificada diferença entre as cultivares quanto à densidade populacional da bactéria em nenhuma das três avaliações realizadas.

No cultivo de primavera, aos 21 dias após o plantio, devido a ausência de plantas com sintomas de murcha bacteriana, não se coletaram amostras de plantas sintomáticas das cultivares Baronesa e Macaca, e a comparação da densidade populacional da bactéria foi realizada somente entre plantas das cultivares Achat, Elvira, Monte Bonito e Trapeira. A análise da variância dos dados, das avaliações feitas em plantas sintomáticas durante o cultivo de primavera, indicou apenas interação entre os fatores densidade

Tabela 1 - Incidência de murcha bacteriana bacteriana em plantas de seis cultivares de batata no campo em dois locais e em duas épocas de cultivo. (Valores médios de Eldorado do Sul (RS), 1996 e Caxias do Sul (RS), 1998).

\begin{tabular}{lcc}
\hline & \multicolumn{2}{c}{ Incidência (\%) } \\
\cline { 2 - 3 } Cultivar & \multicolumn{2}{c}{ Cultivo $^{1}$} \\
\cline { 2 - 3 } & Primavera & Outono \\
\cline { 2 - 3 } Achat & $15,8^{2} \mathrm{~d}$ & 0,0 \\
Baronesa & $43,6 \mathrm{abc}$ & 0,0 \\
Elvira & $28,7 \mathrm{bcd}$ & 0,0 \\
Macaca & $28,7 \mathrm{bcd}$ & 4,1 \\
M. Bonito & $62,8 \mathrm{ab}$ & 1,9 \\
Trapeira & $73,0 \mathrm{a}$ & 0,0 \\
Média & 42,1 & 1,0 \\
CV $(\%)$ & & 33,68 \\
\hline
\end{tabular}

${ }^{1}$ Data do plantio - primavera: 15/10/96; outono: 03/03/98

${ }^{2}$ Médias na coluna, seguidas da mesma letra, não diferem pelo teste de Tukey em nível de $5 \%$ de probabilidade de erro. 
Tabela 2 - População de Ralstonia solanacearum quantificada através de técnicas imunológicas em plantas assintomáticas de seis cultivares de batata. (Valores médios de Eldorado do Sul (RS), 1996 e Caxias do Sul (RS), 1998).

\begin{tabular}{|c|c|c|c|}
\hline \multirow{2}{*}{ Técnica } & \multirow{2}{*}{ Cultivar } & \multicolumn{2}{|c|}{ Cultivo $^{1}$} \\
\hline & & Primavera & Outono \\
\hline \multicolumn{4}{|l|}{ ELISA } \\
\hline & Achat & $0,089^{2} \mathrm{ab}$ & $0,065 \mathrm{ab}$ \\
\hline & Baronesa & $0,167 \mathrm{a}$ & 0,086 a \\
\hline & Elvira & $0,116 a b$ & $0,054 \mathrm{ab}$ \\
\hline & Macaca & $0,073 \mathrm{ab}$ & $0,058 \mathrm{ab}$ \\
\hline & M. Bonito & $0,066 \mathrm{ab}$ & $0,053 \mathrm{ab}$ \\
\hline & Trapeira & $0,058 \mathrm{ab}$ & $0,049 a b$ \\
\hline & Controle $^{3}$ & $0,033 \mathrm{~b}$ & $0,025 \mathrm{~b}$ \\
\hline Média & & 0,086 & 0,056 \\
\hline $\mathrm{CV}(\%)$ & & 8,60 & 4,38 \\
\hline \multicolumn{4}{|c|}{ Imunofluorescência } \\
\hline & Achat & $2,91 \times 10^{3} \mathrm{ab}$ & $9,65 \times 10^{1}$ \\
\hline & Baronesa & $3,87 \times 10^{4} \mathrm{a}$ & $6,96 \times 10^{0}$ \\
\hline & Elvira & $1,92 \times 10^{3} \mathrm{ab}$ & $8,60 \times 10^{1}$ \\
\hline & Macaca & $2,87 \times 10^{2} \mathrm{~b}$ & $1,34 \times 10^{2}$ \\
\hline & M. Bonito & $1,36 \times 10^{3} \mathrm{ab}$ & $1,17 \times 10^{2}$ \\
\hline & Trapeira & $1,41 \times 10^{3} \mathrm{ab}$ & $3,35 \times 10^{1}$ \\
\hline Média & & $7,76 \times 10^{3}$ & $7,9 \times 10^{1}$ \\
\hline $\mathrm{CV}(\%)$ & & 40,73 & 64,53 \\
\hline
\end{tabular}

${ }^{1}$ Data do plantio - primavera: 15/10/96; outono: 03/03/98

${ }^{2}$ Médias na coluna e para cada tipo de avaliação, seguidas da mesma letra, não diferem pelo teste de Tukey em nível de 5\% de probabilidade de erro.

${ }^{3}$ Planta da cultivar Baronesa coletada de parcela em que não houve inoculação com a bactéria.

populacional e época de avaliação. No cultivo de outono, devido à ocorrência de murcha bacteriana apenas em plantas das cultivares Macaca e Monte Bonito, a comparação entre densidades populacionais nas seis cultivares não foi realizada, pois não se coletaram amostras de plantas sintomáticas.

Os resultados obtidos indicam que não houve relação entre o grau de resistência e a densidade populacional de $\boldsymbol{R}$. solanacearum sob a forma latente ou assintomática durante a fase vegetativa da cultura. Isto foi verificado mesmo que a população da bactéria na cultivar Baronesa, que se caracterizou como sendo uma das três cultivares mais suscetíveis (Tabela 1), tenha sido superior ao controle quando se utilizou ELISA e à cultivar Macaca na média do cultivo de primavera, quando se utilizou a técnica de imunofluorescência. Esta tendência da população ser superior na cultivar Baronesa pode ser um indicativo que a utilização de técnicas mais sensíveis de detecção ou quantificação, como a da PCR, pode fornecer melhores informações sobre relação entre o grau de resistência de genótipos de batata e a densidade populacional da bactéria. Por outro lado, as informações obtidas ajudam a elucidar aspectos relacionados à potencialidade que plantas das cultivares de batata mais utilizadas no Brasil representam como substrato de sobrevivência e manutenção de inóculo de $\boldsymbol{R}$. solanacearum. Levando-se em consideração que a cultivar Achat tem demonstrado ser a mais resistente entre as recomendadas para cultivo no Brasil (Tabela 1), ressalta-se a condição de igualdade verificada entre as densidades populacionais da bactéria nesta cultivar em comparação com as outras cultivares utilizadas no experimento. Também foram registradas, em algumas avaliações feitas em plantas assintomáticas das cultivares Baronesa, Elvira e Achat, densidades populacionais que variaram de $10^{4} \mathrm{a}^{1} 0^{5} \mathrm{UIF} \mathrm{g}^{-1}$ de tecido vegetal. Estes níveis populacionais são preocupantes, pois são iguais àqueles obtidos em algumas avaliações feitas em plantas sintomáticas (Tabela 3) e reforça o interesse em se obter genótipos que sejam resistentes a murcha bacteriana, mas que também não permitam que a taxa de infecção latente da bactéria seja alta. A ausência de mais dados sobre a população latente em plantas das cultivares de batata recomendadas para cultivo no Brasil impede que se tenha um padrão de comparação para associar as densidades populacionais observadas neste trabalho com a capacidade epidemiológica de cada cultivar manter o inóculo da bactéria na lavoura. No entanto, a importância de se estabelecer o grau de desenvolvimento de populações latentes em diferentes cultivares reside na possibilidade de, além de estimar a contribuição de cada cultivar para manutenção ou disseminação de inóculo do patógeno, relacionar densidades de população latente de $\boldsymbol{R}$. solanacearum com parâmetros de produção e produtividade. Em amendoim, tem sido determinado que populações latentes do patógeno, em cultivares resistentes, tem afetado vários aspectos relacionados com a produtividade das cultivares, tais como, resistência à seca, fixação biológica de nitrogênio e proliferação de raízes (LIAO et al., 1998).

Atualmente a seleção de cultivares resistentes a murcha bacteriana é realizada utilizandose, como critério, a visualização de plantas com sintomas. Considerando que plantas assintomáticas podem hospedar o patógeno com alta taxa densidade populacional, a observação visual não garante ausência da bactéria. A utilização de técnicas mais rápidas e sensíveis facilitam e agilizam o estudo da 
Tabela 3 - População de Ralstonia solanacearum quantificada através de técnicas imunológicas em plantas com sintomas de murcha de quatro cultivares de batata. (Valores médios de Eldorado do Sul (RS), 1996).

\begin{tabular}{|c|c|c|c|c|c|c|}
\hline \multirow{4}{*}{ Cultivar } & \multicolumn{6}{|c|}{ Técnica } \\
\hline & \multicolumn{3}{|c|}{ ELISA } & \multicolumn{3}{|c|}{ Imunofluorescência } \\
\hline & \multicolumn{3}{|c|}{ Dias após o plantio $^{1}$} & \multicolumn{3}{|c|}{ Dias após o plantio } \\
\hline & 21 & 42 & 68 & 21 & 42 & 68 \\
\hline Achat & $0,410^{2} \mathrm{a}$ & $0,474 \mathrm{a}$ & $0,145 \mathrm{ab}$ & $2,73 \times 10^{7}$ & $1,39 \times 10^{6}$ & $1,99 \times 10^{6}$ \\
\hline Elvira & $0,508 \mathrm{a}$ & $0,530 \mathrm{a}$ & $0,125 \mathrm{ab}$ & $1,95 \times 10^{8}$ & $1,00 \times 10^{8}$ & $7,23 \times 10^{4}$ \\
\hline M. Bonito & $0,341 \mathrm{a}$ & $0,399 \mathrm{a}$ & $0,237 \mathrm{a}$ & $1,14 \times 10^{8}$ & $6,24 \times 10^{6}$ & $2,15 \times 10^{5}$ \\
\hline Trapeira & $0,413 \mathrm{a}$ & $0,366 \mathrm{a}$ & $0,129 \mathrm{ab}$ & $3,18 \times 10^{7}$ & $3,04 \times 10^{6}$ & $2,82 \times 10^{3}$ \\
\hline Controle & $0,031 \mathrm{~b}$ & $0,021 \mathrm{~b}$ & $0,048 \mathrm{~b}$ & & & \\
\hline Média & 0,323 & 0,358 & 0,137 & $9,2 \times 10^{7}$ & $2,77 \times 10^{7}$ & $5,7 \times 10^{5}$ \\
\hline $\mathrm{CV}(\%)$ & & 18,98 & & & 23,02 & \\
\hline
\end{tabular}

${ }^{1}$ Data do plantio - 15/10/96

${ }^{2}$ Médias na coluna, seguidas da mesma letra, não diferem pelo teste de Tukey em nível de 5\% de probabilidade de erro.

população latente. Entretanto, apesar da determinação do grau de resistência de cultivares, baseada na incidência de sintomas não ser totalmente elucidativo sobre a dinâmica populacional de $\boldsymbol{R}$. solanacearum, este tipo de avaliação ainda é essencial devido ao seu menor custo e maior praticidade e viabilidade.

Considerando as três avaliações realizadas, nenhuma das técnicas indicou diferença entre a densidade populacional de $\boldsymbol{R}$. solanacearum presente em plantas murchas das seis cultivares. Este resultado está de acordo com os obtidos por GRIMAULT et al. (1994), os quais indicaram que a densidade populacional de $\boldsymbol{R}$. solanacearum (biovar I) em plantas de tomate com sintomas de murcha apresentava a mesma densidade aos 24 e 34 dias após a inoculação. Um dos prováveis principais motivos que contribuiu para a ocorrência da interação registrada nas plantas sintomáticas entre os fatores densidade populacional, determinado pelas duas técnicas, e época de avaliação, foi a existência de cultivares com ciclos diferentes. Tal situação pode ter influenciado a dinâmica populacional da bactéria nas diferentes cultivares.

\section{REFERÊNCIAS BIBLIOGRÁFICAS}

CASTRO, L. A. S.; DANIELS, J.; COUTO, M. E. O. Utilização do teste de ELISA na diagnose de Pseudomonas solanacearum. In: CONGRESSO BRASILEIRO DE FITOPATOLOGIA, 26., 1993, Aracaju, SE. Resumos... Brasília : Sociedade Brasileira de Fitopatologia, 1993. p.296.

CENTRO INTERNACIONAL DE LA PAPA. Detección con ELISA de virus de la papa. Lima, Perú, 1990. 9p. (Informe anual).
CIAMPI, L.; SEQUEIRA, L. Multiplication of Pseudomonas solanacearum in resistant potato plants and the establishment of latent infections. American Potato Journal, v.57, p.319329,1980

De BOER, S.H.; McCANN, M. Determination of population densities of Corynebacterium sepedonicum in potato stems during growing season. Phytopathology, v.79, p.946-951, 1989.

De BOER, S.H.; McCANN, M. Detection of Corynebacterium sepedonicum in potato cultivars with different propensities to express ring rot symptoms. American Potato Journal, v.67, p.685-694, 1990.

ELPHINSTONE, J.G. et al. Sensitivity of different methods for the detection of Ralstonia solanacearum in potato tuber extracts. OEPP/EPPO, v.26, p.663-678, 1996.

ELPHINSTONE, J.G. Metodos de detectión de Pseudomonas solanacearum en cultivos de papa. In: TALLER SOBRE ENFERMEDADES BACTERIANAS DE LA PAPA, 1993, Brasília, DF. Anais... Brasília : EMBRAPA/CNPH, 1994. p.23-32.

GRAHAM, J.; JONES, D.A.; LLOYD, A.B. Survival of Pseudomonas solanacearum race 3 in debris and latently infected potato tubers. Phytopathology, v.69, p.1100-1103, 1979.

GRIMAULT, V.; ANAIS, G.; PRIOR, P. Distribuition of Pseudomonas solanacearum in the stem tissues of tomato plants with different levels of resistance to bacterial wilt. Plant Pathology, v.43, p.663-668, 1994.

GRIMSLEY, N.; WANG, J.-F. Chair's perpective: host resistance. In: INTERNATIONAL BACTERIAL WILT SYMPOSIUM, 2., 1997, Guadeloupe. Proceedings... Guadeloupe : ACIAR, 1998. p.197-199.

HAYWARD. A.C. Biology and epidemiology of bacterial wilt caused by Pseudomonas solanacearum. Annual Review of Phytopathology, v.29, p.65-87, 1991. 
LIAO, B.S. et al. Relationship between latent infection and groundnut bacterial wilt resistance. In: INTERNATIONAL BACTERIAL WILT SYMPOSIUM, 2., 1997, Guadeloupe. Proceedings... Guadeloupe : ACIAR, 1998. p.294-299.

LOPES, C.A. Brasil: Situação da murcha bacteriana da batata no Brasil. In: TALLER SOBRE ENFERMEDADES BACTERIANAS DE LA PAPA, 1993, Brasília, DF. Anais... Brasília : EMBRAPA/CNPH, 1994. p.38.

McDONALD, J.; BORREL, B. Development of post harvest testing in Canada. American Potato Journal, v.68, p.115120, 1991.

MOFFET, M.L.; GILES, J.E.; WOOD, B.A. Survival of Pseudomonas solanacearum biovars 2 and 3 in soil: effect of moisture and soil type. Soil Biology and Biochemical, v.15, p.587-591, 1983.

ROBINSON, A. Serological detection of Pseudomonas solanacearum by ELISA. In: INTERNATIONAL BACTERIAL WILT SYMPOSIUM, 1992, Taiwan. Proceedings ... Taiwan: ACIAR, 1993. p.54-61.

Van VUURDE, J.W.L. Imunofluorescence colony staining. In: HAMPTON, R.; BALL, E.; DE BOER, S. Serological methods for detection and identification of viral and bacterial plant pathogens. St. Paul : APS, 1990. p.299-305.

YOSSEN, V.E. et al. Titulação da virulência de estirpes de Ralstonia solanacearum resistentes a antibióticos. Fitopatologia Brasileira, v.23, p.495-497, 1998. 